\title{
Equatorial electrojet in the Indian region during the geomagnetic storm of 13-14 November 1998
}

\author{
H Chandra $^{1, *}$, R G Rastogi ${ }^{1}$, R K Choudhary ${ }^{2}$ and Som Sharma ${ }^{1}$ \\ ${ }^{1}$ Physical Research Laboratory, Ahmedabad 380 009, India. \\ ${ }^{2}$ Space Physics Laboratory, Vikram Sarabhai Space Centre, Thiruvananthapuram 695 002, India. \\ ${ }^{*}$ Corresponding author. e-mail: hchandra@prl.res.in
}

The geomagnetic storm of November 1998 is a unique event where IMF-Bz remained southward with values exceeding $-15 \mathrm{nT}$ for more than a day. The SYM/H index decreased from about $07 \mathrm{hr}$ on 13 November 1998 reaching a minimum of about $-120 \mathrm{nT}$ around midnight of 13-14 November 1998. Features of the equatorial electrojet in the Indian region are studied during the geomagnetic storm event of 13-14 November 1998, based on the geomagnetic data from the chain of observatories in India. Sudden northward turning of IMF-Bz for a very short duration around $08 \mathrm{hr}$ on 13 November 1998 resulted in a small and very short duration counter electrojet. A strong $(-50 \mathrm{nT})$ and a long duration counter electrojet, right from 08 to $13 \mathrm{hr}$ on 14 November 1998 was observed resulting in the absence of equatorial Es at Thumba. Absence of the equatorial ionization anomaly was also observed as seen from the ionograms over Thumba and ionspheric data from Ahmedabad. The delayed effect on 14 November 1998 is due to the disturbance dynamo effect.

\section{Introduction}

The day-to-day variability of the equatorial ionosphere, particularly during geomagnetic disturbed conditions, is not completely understood yet. There have been a number of studies in recent years on the response of equatorial ionosphere to different space weather events. The association between the IMF-Bz and the ionospheric drifts near dip equator, a measure of the electric field in ionosphere, was first reported by Rastogi and Chandra (1974). Rastogi and Patel (1975) noted that large and quick changes in the direction of IMF from southward to northward are associated with the imposition of an interplanetary electric field directed from dusk-to-dawn direction (eastward in the night sector and westward in the day side sector). Prompt penetration electric fields associated with the sudden turning of the interplanetary magnetic field component $\mathrm{Bz}$ from northward to southward or from southward to northward and the delayed disturbance dynamo fields, change the electrodynamics of the equatorial ionosphere and thus affect the features of equatorial ionosphere like the equatorial electrojet, equatorial Esq, equatorial ionization anomaly and the equatorial spread-F. The prompt penetrating electric field associated with the sudden southward turning of the IMF-Bz is eastward on the dayside and westward during night side. Therefore, it enhances the daytime eastward electric field. In the recovery phase of the storm, the electric field due to shielding layer penetrates to equatorial latitudes as an overshielding electric field with opposite polarity, westward during dayside and eastward during night side (Kelley et al. 1979). In addition to the prompt penetration electric fields, there are disturbance dynamo electric fields caused by the disturbed time winds that

Keywords. Equatorial electrojet; equatorial ionosphere; geomagnetic storms. 
produce long-lasting dynamo electric field that affect the equatorial electrodynamics within few hours from the onset of a storm and continue for several hours (Blanc and Richmond 1980). The disturbance dynamo is of opposite polarity (westward during day and eastward during night).

There have been several case studies describing the storm time effects in equatorial ionosphere at a particular longitude sector (Basu et al. 2001a, b; Sastri et al. 2002; Abdu et al. 2003; Maruyama 2006) or at more than one longitude sectors (Abdu et al. 2007; Tulasi Ram et al. 2008; Bagia et al. 2011; Rastogi et al. 2014a).Most of such studies are based on sudden turnings of IMF-Bz. However, there are space weather events with large or no increase in solar wind velocity, large or no increase in the solar wind proton density or large changes in both solar wind velocity and proton density. The changes in IMF-Bz also may be sudden and large for short duration of time or slow changes for a long duration. For clear understanding of the geomagnetic storms and associated effects in the ionosphere, it is necessary to study different types of space weather events.

The geomagnetic storm of November 1998 is unique where IMF-Bz remained southward with values exceeding $-15 \mathrm{nT}$ for more than a day. In the present paper, we report the features of the equatorial electrojet in the Indian region based on the geomagnetic data at the chain of observatories in India and the changes in the equatorial E-region as seen from ionosonde observations at Thumba. Effects in the equatorial ionization anomaly are inferred from the ionograms at Thumba and from the ionospheric data over Ahmedabad.

\section{Results}

\subsection{Interplanetary and solar wind parameters}

The time variations of the interplanetary magnetic field component $\mathrm{Bz}$, solar wind parameters (flow speed, proton density and flow pressure), electric field of solar wind origin $(\mathrm{VxBz})$ and the SYM/H index for the 4-day period, 12-15 November 1998 are shown in figure 1. On 12 November 1998, there is no significant variation of IMF-Bz. The values are close to zero till local mid-day $\left(75^{\circ} \mathrm{E}\right)$ and between zero and $6 \mathrm{nT}$ up to $06 \mathrm{hr}$ of 13 November 1998. Sudden southward turning of IMF-Bz is noticed just before $06 \mathrm{hr}$ on 13 November with values reaching around $-15 \mathrm{nT}$ for 3 hours. It turned northward at about $08 \mathrm{hr}$ to about $12 \mathrm{nT}$ and then again turned southward around $10 \mathrm{hr}$. IMF$\mathrm{Bz}$ remained southward from $10 \mathrm{hr}$ of 13 November to $10 \mathrm{hr}$ of 14 November 1998 with values up to $-18 \mathrm{nT}$. Thus IMF-Bz remained strongly southward for a long period of 24 hours and this is unique about the event. Later it turned northward for a very short time around noon and again around $16 \mathrm{hr}$ but it remained southward with values up to $-15 \mathrm{nT}$. It recovered slowly to normal values and on 15 November remained within $\pm 5 \mathrm{nT}$.

There was no big change in the flow speed. It was around $350 \mathrm{~km} / \mathrm{s}$ on 12 November but increased to $400 \mathrm{~km} / \mathrm{s}$ from $06 \mathrm{hr}$ on 13 November and remained between 350 and $450 \mathrm{~km} / \mathrm{s}$ on 14 and 15 November. The proton density did show large changes varying from about 5 per $\mathrm{cm}^{3}$ on 12 and 15 November to peak values of more than 40 per $\mathrm{cm}^{3}$ around $07 \mathrm{hr}$ on 13 November and again around $17 \mathrm{hr}$ on 14 November. As a consequence, the flow pressure shows peaks similar to the peaks in proton density. The variation of the electric field of magnetospheric origin is just opposite to the variation of the IMF-Bz with values up to $7 \mathrm{mV} / \mathrm{m}$ for most part of the two-day period of 13-14 November. The $\mathrm{SYM} / \mathrm{H}$ index shows decrease from about $07 \mathrm{hr}$ on 13 November reaching a minimum of about $-120 \mathrm{nT}$ around midnight of 13-14 November 1998. Another feature observed is periodic variation in SYM/H index with a periodicity of about 4 hours.

\subsection{Geomagnetic field variations}

Data from a chain of seven geomagnetic observatories in India are used in the present study. The geographic coordinates and the dip angle of the observatories at Trivandrum (TRD), Kodaikanal (KOD), Pondicherry (PON), Hyderabad (HYD), Alibag (ABG), Ujjain (UJJ) and Sabawala (SAB) are listed in table 1 . The chain of the observatories covers the region from dip equator to $\mathrm{Sq}$ focus.

The mean daily variations of the range in $\mathrm{H}(\mathrm{Sq} \mathrm{H})$ for the month of November 1998 at the seven stations are shown in figure 2(a). The mean daily range in $\mathrm{H}$ is highest at TRD, closest to the dip equator with a value of $82 \mathrm{nT}$ just before noon. The mean daily range decreases with increasing dip angle with values of $63,54,50,50,37$ and $15 \mathrm{nT}$ for the stations KOD, PON, HYD, ABG, UJJ and $\mathrm{SAB}$. Another interesting point to note is that the time of the maximum value of $\mathrm{Sq} \mathrm{H}$ is gradually delayed at stations away from the magnetic equator. It occurs at $11 \mathrm{hr}$ at KDK, around mid-day at TRD, PON, HYD and around $1230 \mathrm{hr}$ at ABG, UJJ and SAB. The peak occurs about an hour earlier at KDK than at TRD even though both the stations are close to the dip equator and the longitude difference is only a degree. In a recent study based on 40 years of data, the time of maximum in the daily range of $\mathrm{H}$ was also shown to be around mid-day at TRD and around $1300 \mathrm{hr}$ at ABG by Rastogi et al. (2014b). The earlier peak at KDK 


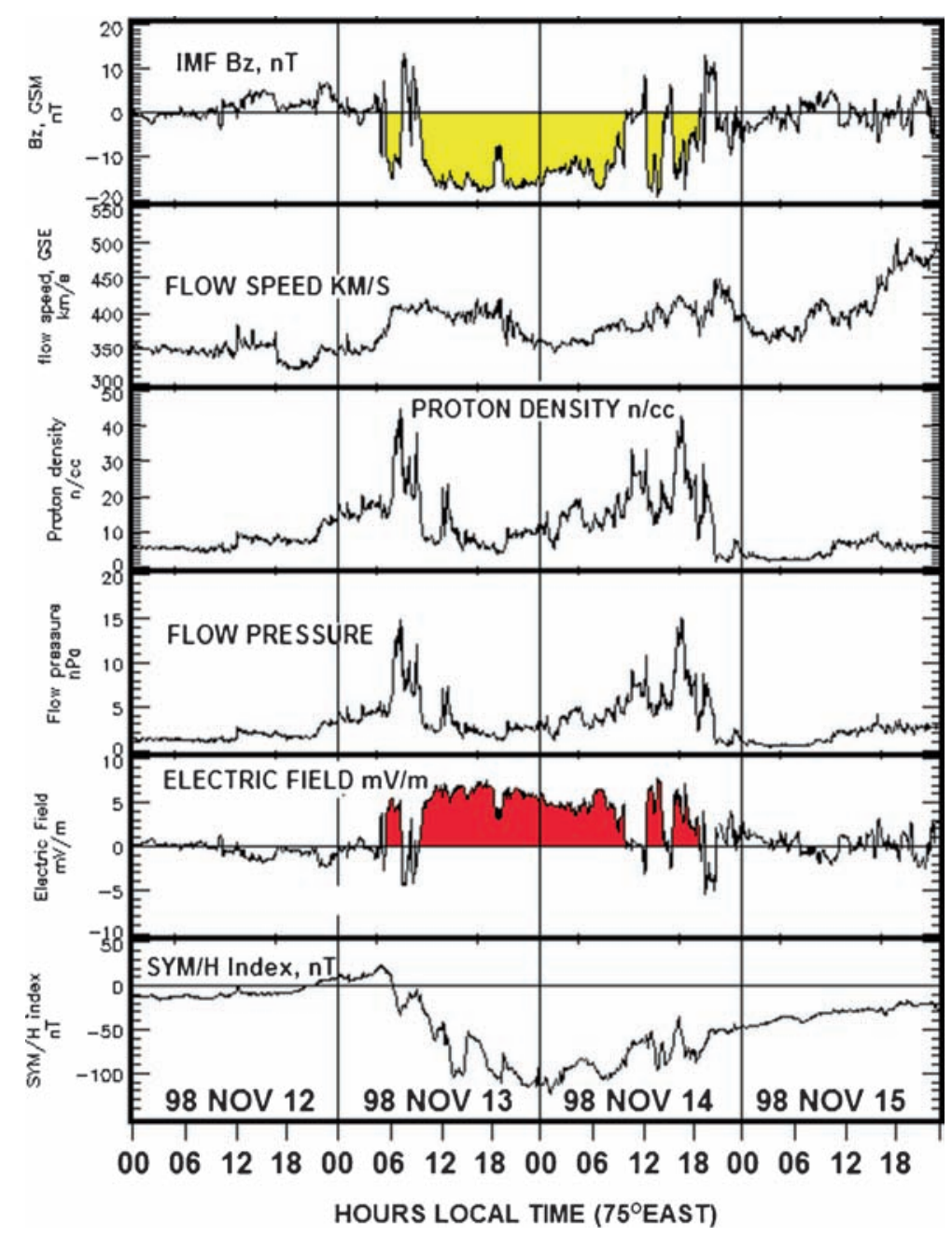

Figure 1. Variations of the IMF-Bz, solar wind parameters flow speed, proton density, flow pressure, interplanetary electric field and SYM/H index during the 4-day period of 12-15 November 1998.

Table 1. Stations with geographic coordinates and dip angle.

\begin{tabular}{lcccc}
\hline Station name & $\begin{array}{c}\text { Station } \\
\text { code }\end{array}$ & $\begin{array}{c}\text { Latitude } \\
\left({ }^{\circ} \mathrm{N}\right)\end{array}$ & $\begin{array}{c}\text { Longitude } \\
\left({ }^{\circ} \mathrm{E}\right)\end{array}$ & $\begin{array}{c}\text { Dip angle } \\
\left({ }^{\circ} \mathrm{N}\right)\end{array}$ \\
\hline Trivandrum & TRD & 8.5 & 76.5 & 1.6 \\
Kodaikanal & KOD & 10.2 & 77.5 & 5.0 \\
Pondicherry & PON & 11.9 & 79.9 & 9.2 \\
Hyderabad & HYD & 17.4 & 78.6 & 21.7 \\
Alibag & ABG & 18.6 & 72.9 & 25.7 \\
Ujjain & UJJ & 23.2 & 76.8 & 33.9 \\
Sabawala & SAB & 30.4 & 77.8 & 46.1 \\
\hline
\end{tabular}

has resulted in lower values of $\Delta \mathrm{H}$ in the afternoon as compared to values at PON and HYD. The mean daily range of $\mathrm{H}$ for November 1998 for the seven stations is plotted as a function of dip angle in figure 2(b). It decreases rapidly with the dip angle up to $10^{\circ}$ (PON) as expected close to the dip equator and then slowly up to $25^{\circ}$ (ABG). There is rapid decrease from $\mathrm{ABG}$ to $\mathrm{SAB}$.

The disturbance daily variations in $\mathrm{H}$ for the seven stations during the period 12-15 November
1998 are shown in figure 3(a). These are obtained by subtracting the mean quiet day daily variations in $\mathrm{H}$ for the respective stations $(\mathrm{Hd}-\mathrm{Hq})$. For comparison, Dst index is also shown in the figure. There is a similarity in the nature of daily variations of disturbance daily variations in $\mathrm{H}$ at different stations with the daily variations of the Dst index. However, during the daytime hours on 14 November, the disturbance daily variations at stations closer to the dip equator (TRD, KOD, PON) show large decreases as compared to other stations. The magnitude of the mid-day decrease is largest at dip equator and systematically reduces with increasing dip angle. The variations with dip angle of the (Hd - Hq) for near mid-day (10-12 LT) values on 14 November 1998 and for the pre-midnight (20-24 LT) on 13 November 1998 are shown in figure 3(b). The values in the pre-midnight hours of 13 November vary between -130 and $-160 \mathrm{nT}$. But for the 10-12 LT period on 14 November 1998, the values vary rapidly from dip equator to $10^{\circ}$ dip $(-160$ to $-100 \mathrm{nT}$ ) and then slowly vary to $-80 \mathrm{nT}$ at 

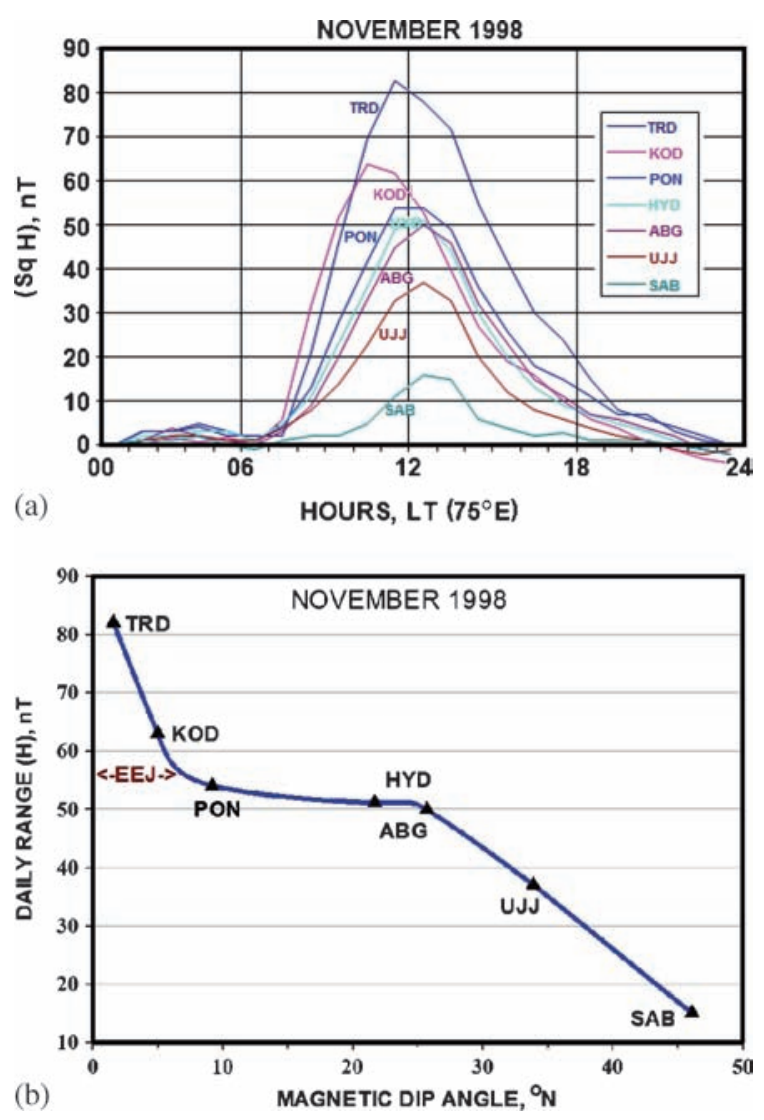

Figure 2. (a) Monthly mean solar quiet day variations of the horizontal component of the geomagnetic field at the seven stations in India. (b) Monthly mean daily range of $\mathrm{H}$ for November 1998 plotted as a function of dip angle.

$\mathrm{SAB}$, the northernmost station of the chain. The decreases with respect to night time level $(06 \mathrm{hr})$ are around $100 \mathrm{nT}$ for TRD, $60 \mathrm{nT}$ at KDK and 25 $\mathrm{nT}$ at PON. Thus these decreases between 08 and $14 \mathrm{hr}$ and peaking around noon on 14 November are due to large westward currents and of ionospheric origin. The large values close to the dip equator are due to the enhanced conductivity as during normal electrojet.

To study the equatorial electrojet strength during the 4-day period, the daily variations of the deviations in $\mathrm{H}(\Delta \mathrm{H})$, at TRD and $\mathrm{ABG}$, the EEJ strength $(\Delta \mathrm{H}$ EEJ $)$ as determined from the difference of $\Delta H$ at TRD and ABG, and DST index are shown in figure 4 . The figure shows clearly the normal EEJ on 12, 13 and 15 November 1998 but a strong $(-50 \mathrm{nT})$ and a long duration counter electrojet right from 08 to 13 LT on 14 November 1998. The decrease in Dst index started from about 06 LT on 13 November 1998 and reached maximum decrease of about $-135 \mathrm{nT}$ around midnight of $13-$ 14 November. However, the electrojet is normal on 13 November 1998, except for a very short duration counter electrojet (about $-10 \mathrm{nT}$ ) around $08 \mathrm{hr}$ on 13 November. This could be associated with
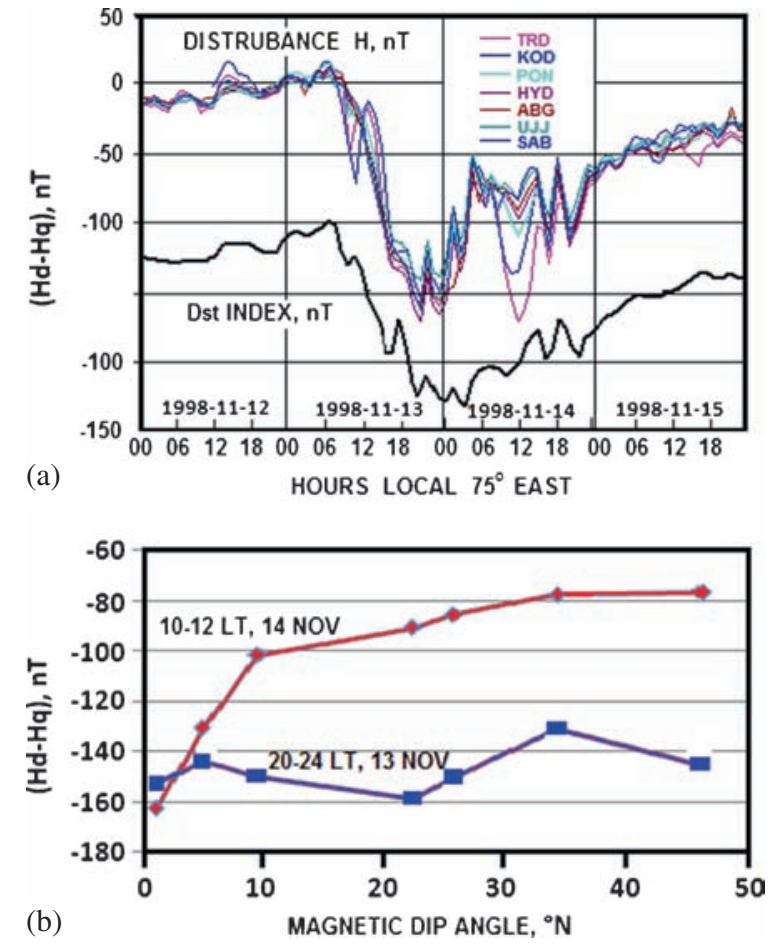

Figure 3. (a) Disturbance daily variations of the geomagnetic $\mathrm{H}$ component at the seven stations in India for the 4day period 12-15 November 1998. (b) The variations with dip angle of the disturbance daily values ( $\mathrm{Hd}-\mathrm{Hq}$ ) for near mid-day (10-12 LT) on 14 November 1998 and for the pre-midnight (20-24 LT) on 13 November 1998.

the sudden northward turning of IMF-Bz. There is southward turning of IMF-Bz around $06 \mathrm{hr}$ on 13 November but its effect is not seen in the magnetic field variation due to absence of sufficient ionization in E-region.

\subsection{Equatorial ionosphere over Thumba}

The ionograms for 1100, 1130 and 1200 LT at Thumba, located close to dip equator are reproduced both for 13 November (red) and 14 November 1998 (blue) in figure 5. On 13 November, equatorial type Esq traces are clearly seen but there is no Esq on 14 November 1998. This indicates westward electric field associated with the counter electrojet. The absence of Esq was seen even up to $12: 30 \mathrm{hr}$. From the F-region traces, one clearly notices lower values of the F-layer height and higher values of the critical frequency of F2 layer (foF2) around mid-day on 14 November 1998 as compared to 13 November 1998. This is associated with the absence of the vertical upward $\mathrm{E} \times \mathrm{B}$ drift and as a consequence, absence of equatorial ionization anomaly due to the westward electric field during the counter electrojet period. One can also notice clear F1 region on 14 November 1998. 
The absence of equatorial ionization anomaly on 14 November 1998 is also confirmed from the plots of F-layer parameters over Ahmedabad. Hourly values of foF2, the critical frequency of the $\mathrm{F} 2$ layer and $\mathrm{h}^{\prime} \mathrm{F}$, the minimum virtual height of the F2 layer are plotted for 13 November 1998 (blue) and 14 November 1998 (red) in figure 6. The monthly mean values of the parameters for November 1998 are also shown in the figure (black). Looking at the duration of the counter electrojet on 14 November 1998, the foF 2 values are lower on 14 November as compared to the values on 13 November or the monthly mean values. The foF 2 at $09 \mathrm{hr}$ is $10 \mathrm{MHz}$ on 13 November 1998 but only $8 \mathrm{MHz}$ on 14 November 1998, a decrease of about $20 \%$ amounting to a decrease of about $40 \%$ in electron density. Thus, the values of foF 2 are higher at Thumba and lower at Ahmedabad on 14 November than on 13 November. This is consistent with the absence of the equatorial ionization anomaly.

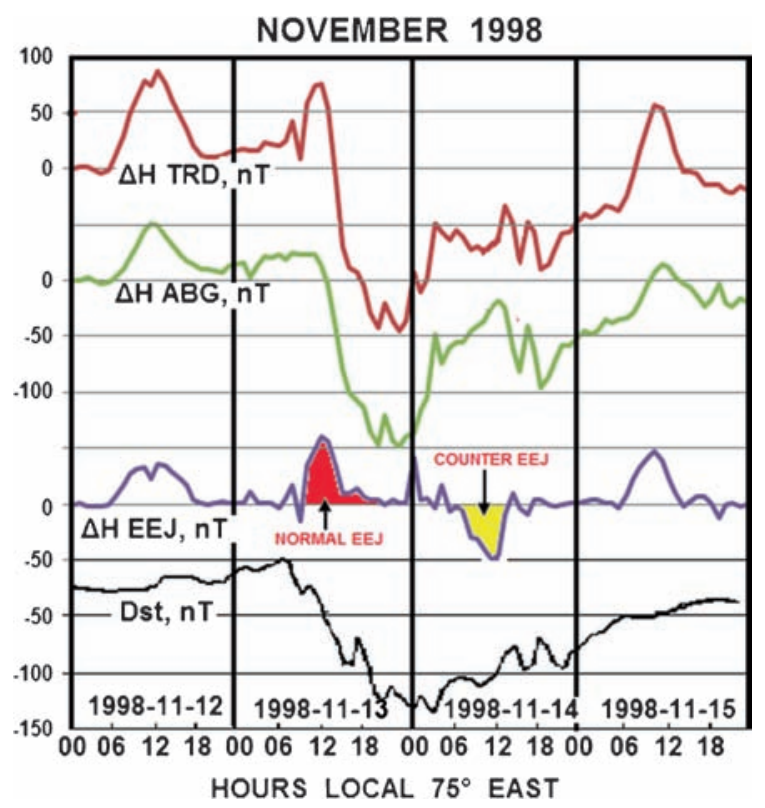

Figure 4. Daily variations of the deviations in $\mathrm{H}$ at TRD, ABG, EEJ strength and Dst index for the 4-day period 12-15 November 1998.
There is no significant change seen in the values of $\mathrm{h}^{\prime} \mathrm{F}$ on the two days.

\section{Discussion}

Electrodynamics plays an important role in the equatorial ionosphere. Variability in the electric field of the quiet day ionospheric dynamo origin or of the geomagnetic disturbance origin is known to affect the features of the equatorial ionosphere. The space weather event of 13-14 November 1998 was unique with southward turning of IMF-Bz and strong southward IMF-Bz persisting for 24 hours. This caused a strong and long duration counter electrojet from about $08 \mathrm{hr}$ in the morning to about $13 \mathrm{hr}$ on 14 November 1998 that resulted in the absence of Esq and of the absence of equatorial ionization anomaly. Sudden northward turning of IMF-Bz on 13 November for a small duration triggered a small and brief counter electrojet. Even though the IMF-Bz turned southward around $10 \mathrm{hr}$ on 13 November and remained southward for more than 24 hours, it did not affect the ionosphere on 13 November when a normal electrojet was noticed. A long duration counter electrojet was observed from 08 to $13 \mathrm{hr}$ on 14 November as seen from the geomagnetic field variations at the Indian stations. The absence of equatorial Es and of the ionization anomaly, as seen from the ionograms at Thumba, confirm the reversal of the electric field (delayed) due to disturbance dynamo effect. The ionospheric data over Ahmedabad also confirm the absence of the equatorial ionization anomaly on 14 November with lower values of foF2 as compared to that on 13 November. The decrease in foF 2 over Ahmedabad amounts to a decrease of $40 \%$ in ionization.

Subrahmanyam et al. (2005) have studied the response of the magnetic storm of 13 November 1998 based on ion density measurements from RPA onboard SROSS-C2 satellite data and GPS data. From the SROSS-C2 data, the ionization anomaly peak was normally found to occur around $16^{\circ}-$ $20^{\circ} \mathrm{N}$ (Geog.). However, the ionization anomaly

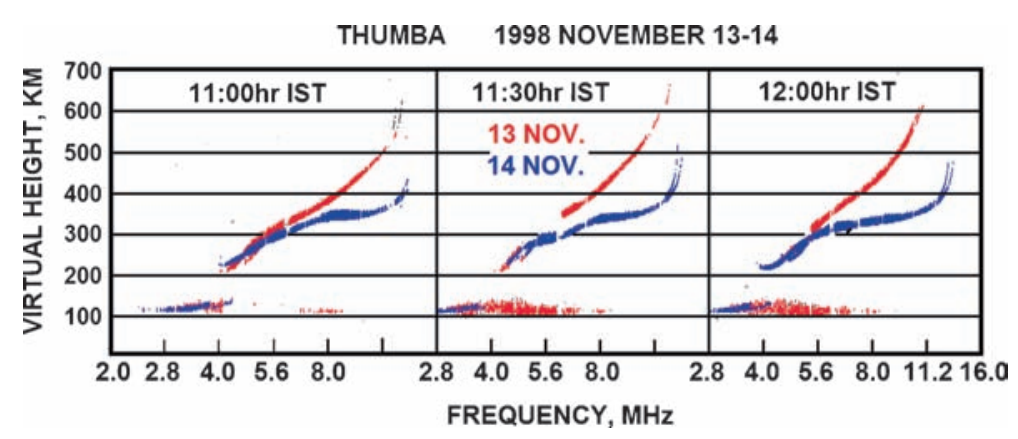

Figure 5. Ionograms at Thumba for 1100, 1130 and $1200 \mathrm{hr}$ on 13 (red) and 14 (blue) November 1998. 


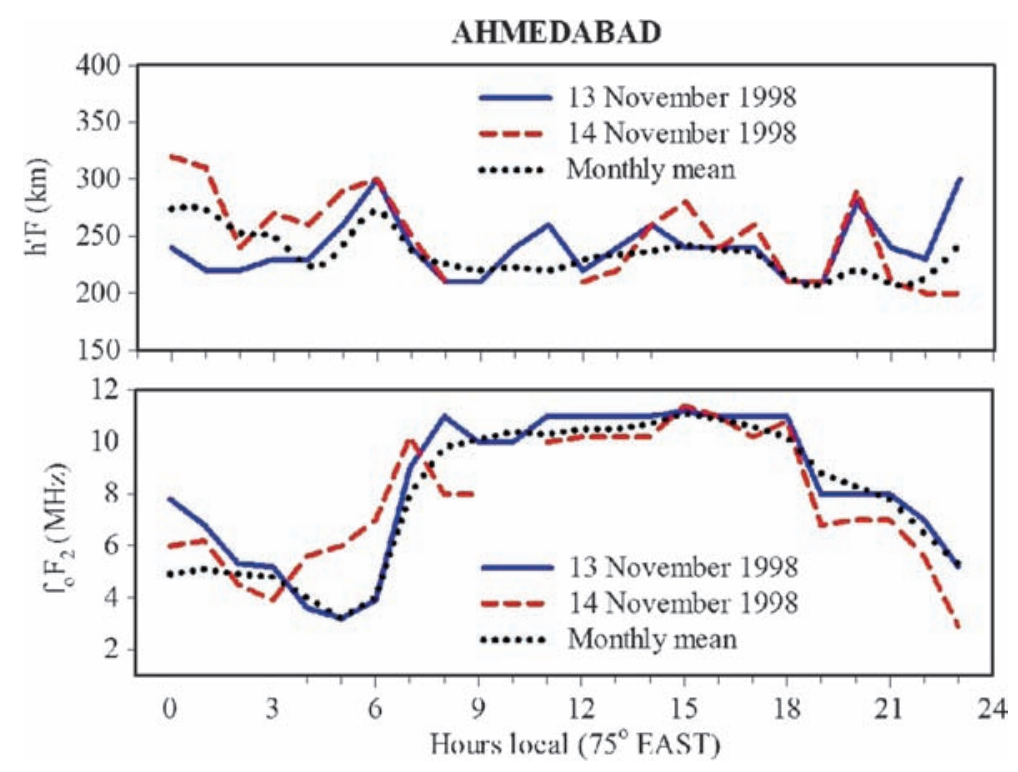

Figure 6. Daily variations of the critical frequency (foF2) and minimum virtual height ( $\mathrm{h}^{\prime} \mathrm{F}$ ) of the F-layer over Ahmedabad for 13 (blue) and 14 (red) November 1998. The monthly mean variations are also shown (black).

was absent on 14 November 1998 and there was decrease in ionization. The ionization density around $12^{\circ} \mathrm{N}$ was less by a factor of about 3 on 14 November 1998 compared to that on a relatively quiet day (11 November 1998). Beyond $24^{\circ} \mathrm{N}$, the ionization density was more or less comparable to that on other days. GPS data showed the ionospheric time delay on 14 November 1998 smaller by about $50 \%$ as compared to other days. This is close to the decrease of about $40 \%$ ionization at Ahmedabad. They suggested weakening of the electric field due to the disturbance dynamo effect.

\section{Conclusion}

- The sudden southward turning of IMF-Bz around $06 \mathrm{hr}$ on 13 November 1998 did not show any signature on the geomagnetic $\mathrm{H}$ field at the Indian stations due to the night time (no appreciable conductivity in the E-region of the ionosphere).

- Sudden northward turning of IMF-Bz for a very short duration around $08 \mathrm{hr}$ on 13 November 1998 caused a decrease in $\mathrm{H}$ at Trivandrum and a small and very short duration counter electrojet.

- The IMF-Bz turned southward around $10 \mathrm{hr}$ on 13 November 1998 with values of about $-15 \mathrm{nT}$ for 24 hours. There was normal electrojet on 13 November 1998.

- A strong (-50 nT) and long duration counter electrojet was seen on 14 November 1998 from 08 to $13 \mathrm{hr}$. The latitudinal variation of the disturbance daily variations in $\mathrm{H}(\mathrm{Hd}-\mathrm{Hq})$ during mid-day also showed large westward current of ionospheric origin. The absence of equatorial
Es at Thumba during this time confirmed the reversal of the electric field to westward.

- The ionograms at Thumba also showed absence of equatorial ionization anomaly with higher foF 2 on 14 November than on 13 November and lower F2 layer height on 14 November than on 13 November during mid-day. Lower values of foF2 on 14 November than on 13 November at Ahmedabad (anomaly crest region) confirm the absence of equatorial ionization anomaly.

- The delayed and the long duration westward electric field observed is due to the disturbance dynamo effect.

\section{Acknowledgements}

Thanks are due to Indian National Science Academy, New Delhi for providing Honorary Professorship to one of the authors (RGR) and to the Director, Physical Research Laboratory, Ahmedabad for the facilities provided to the authors (RGR and HC). Thanks are also due to J H King and Papitashwlli at Adnet System NASA GSFC and C D Aweb for the solar wind data, Space Physics Interactive Data Resources (SPIDR) Boulder, USA, World Data Centre for Geomagnetism Kyoto, Japan, Indian Institute of Geomagnetism, Navi Mumbai, India and Space Physics Laboratory, Thiruvananthapram, India. Thanks are also due to Rahul Shah for technical assistance.

\section{References}

Abdu M A, Batista I S, Takahashi H, MacDougall J, Sobral J H, Medeiros A F and Trivedi N B 2003 Magnetospheric disturbance induced equatorial plasma bubble development and dynamics; J. Geophys. Res. 108 1449, doi: 10.1029/2002JA009721. 
Abdu M A, Maruyama T, Batista I S, Saito S and Nakamura M 2007 Ionospheric response to the October 2003 superstorm: Longitude/local time effects over the equatorial, low and middle latitudes; J. Geophys. Res. 112 A10306, doi: 10.1029/2006.JA012228.

Bagia M S, Iyer K N, Joshi H P, Thampi S V, Tsugawa T, Ravindran S, Sridharan R and Pathan B M 2011 Lowlatitude ionospheric-thermospheric response to storm time electrodynamical coupling between high and low latitudes; J. Geophys. Res. 116 A01303, doi: 10.1029/ 2010JA015845.

Basu S, Basu Su, Groves K M, Yeh H C, Su S-Y, Rich F J, Sultan P J and Keskinen M J 2001a Response of the equatorial ionosphere in the South Atlantic region to the great magnetic storm of July 15, 2000; Geophys. Res. Lett. $283577-3580$.

Basu Su, Basu S, Valladares C E, Yeh H C, Su S Y, Mackenzie E, Sultan P J, Aarons J, Rich F J, Doherty J P, Groves R M and Bullet T W 2001b Ionospheric effects of major magnetic storms during the International Space Weather Period of September and October 1999: GPS observations VHF/UHF installations and in situ density structures at middle and equatorial latitudes; J. Geophys. Res. 106 30,389-30,413.

Blanc M and Richmond A D 1980 The ionospheric disturbance dynamo; J. Geophys. Res. 85 1669-1688.

Kelley M C, Fejer B G and Gonzales C A 1979 An explanation for anomalous ionospheric electric field associated with a northward turning of the interplanetary magnetic field; Geophys. Res. Lett. 6 301-304.

Maruyama T 2006 Extreme enhancement in total electron content after sunset on 8 November 2004 and its connection with storm enhanced density; Geophys. Res. Lett. 33 L20111, doi: 10.1029/2006GL027367.

Rastogi R G and Chandra H 1974 Interplanetary magnetic field and the equatorial ionosphere; J. Atmos. Terr. Phys. 36(2) 377-379.

Rastogi R G and Patel V L 1975 Effect of interplanetary magnetic field on the ionosphere over the magnetic equator; Proc. Indian Acad. Sci. A 82 121-141.

Rastogi R G, Chandra H, Janardhan P, Hoang Thai Lan, Louis Condori, Pant T K, Prasad D S V V D and Reinisch B 2014a Ionospheric spread-F during the magnetic storm of 22 January 2004 at stations in Asian zone; J. Earth Syst. Sci. 123 1273-1285.

Rastogi R G, Chandra H, Janardhan P and Rahul Shah 2014b Equatorial and mid-latitude ionospheric currents over the Indian region based on 40 years of data at Trivandrum and Alibag; Ind. J. Radio Space Phys. 43 $274-283$.

Sastri J H, Niranjan K and Subbarao K S V 2002 Response of the equatorial ionosphere in the Indian (midnight) sector to the severe magnetic storm of July 15, 2000; Geophys. Res. Lett. 29, doi: 10.1029/2002GL015133.

Subrahmanyam P, Jain A R, Singh L and Garg S C 2005 Role of neutral wind and storm time electric fields inferred from the storm time ionization distribution at low latitudes: in-situ measurements by Indian satellite SROSS-C2; Ann. Geophys. 23 3289-3299.

Tulasi Ram S, Rama Rao P V S, Prasad D S V V D, Niranjan K, Gopi Krishna S, Sridharan R and Ravindran S 2008 Local time-dependent response of post-sunset ESF during geomagnetic storms; J. Geophys. Res. 113 A07310, doi: 10.1029/2007JA012922. 